\title{
A Search for a Low Anisotropic Superconductor
}

\section{A. A. Khurram ${ }^{1}$, Nawazish A. Khan ${ }^{2}$}

${ }^{1}$ Experimental Physics Labs, National Centre for Physics, Quaid-i-Azam University, Islamabad, Pakistan; ${ }^{2}$ Materials Science Laboratory, Department of Physics, Quaid-i-Azam University, Islamabad, Pakistan.

Email: khuram_qau@yahoo.com

Received July $27^{\text {th }}, 2009$; revised September $12^{\text {th }}, 2009$; accepted September $17^{\text {th }}, 2009$.

\begin{abstract}
In this article, we have given a review of thallium based $\left(\mathrm{Tl}_{m} \mathrm{Ba}_{2} \mathrm{Ca}_{n-1} \mathrm{Cu}{ }_{n} \mathrm{O}_{2 n+2}\right)$ and copper based $\left(\mathrm{CuBa} \mathrm{Ca}_{n-1} \mathrm{Cu}_{n} \mathrm{O}_{2 n+4}\right)$ high temperature superconductors. This review article is based on the methods of preparation in the form of bulk and thin films and their physical properties. We have also studied the sources of anisotropy and methods of lowering it via changing the composition of charge reservoir layer and developing a better inter-plane coupling.
\end{abstract}

Keywords: Review Article, $\mathrm{Tl}_{m} \mathrm{Ba}_{2} \mathrm{Ca}_{n-1} \mathrm{Cun} \mathrm{O}_{2 n+2}$ and $\mathrm{CuBa}_{2} \mathrm{Ca}_{n-1} \mathrm{Cu}_{n} \mathrm{O}_{2 n+4}$ Superconductors, Synthesis, Physical Properties

\section{Introduction}

One of the general features of high temperature superconductors is the anisotropy parameter $\left[\gamma=\rho_{\mathrm{c}} / \rho_{\mathrm{ab}}=\xi_{\mathrm{ab}} / \xi_{\mathrm{c}}\right]$ which comes from their layered structure. The technological critical temperature and irreversibility field which play very important role in the use of high $T_{c}$ superconductors in various applications are strongly related to the anisotropy parameter as $\mathrm{Z}==\mathrm{T}_{\mathrm{c}} / \gamma$ and $\mathrm{H}_{\mathrm{irr}}=\mathrm{H}_{\mathrm{c} 2} / \gamma$ respectively The understanding of the sources of anisotropy in these layered cuprates is essential to accomplish the direly needed isotropic superconductor; i.e. like BCS superconductor. Therefore, it is very important to search for a superconducting material which has higher critical temperature, $T_{c}$, critical current density and as well as lower anisotropy. The thallium based superconductors $\mathrm{Tl}_{m} \mathrm{Ba}_{2} \mathrm{Ca}_{n-1} \mathrm{Cu}_{n} \mathrm{O}_{2 n+2}(m=1,2 ; n=1,2,3,4,5)$ are superior over other cuprates due to their higher $\mathrm{T}_{\mathrm{c}}, \mathrm{J}_{\mathrm{c}}, \mathrm{H}_{\mathrm{irr}}$ and low microwave surface resistances. The maximum critical temperature achieved in both the families of thallium based superconductors is $123 \mathrm{~K}$ and $127 \mathrm{~K}$ and current densities are of the order of $10^{6} \mathrm{~A} / \mathrm{cm}^{2}$. Another family of oxides which has comparable superconducting characteristics as thallium based compounds but with lower anisotropy is $\mathrm{Cu}_{m} \mathrm{Ba}_{2} \mathrm{Ca}_{n-1} \mathrm{Cu}_{n} \mathrm{O}_{2 n+2}(m=1 n=1,2,3,4,5)$. The major disadvantage associated with these superconductors is their preparation under very high pressures i.e. $4 \mathrm{GPa}$, which makes their large scale production difficult. However, the superconducting properties of $\mathrm{Tl}_{m} \mathrm{Ba}_{2} \mathrm{Ca}_{n-1}$ $\mathrm{Cu}_{n} \mathrm{O}_{2 n+2}$ and $\mathrm{Cu}_{m} \mathrm{Ba}_{2} \mathrm{Ca}_{n-1} \mathrm{Cu}_{n} \mathrm{O}_{2 n+2}$ are combined in a new superconductor family which is represented as $\left(\mathrm{Cu}_{1-\mathrm{x}} \mathrm{Tl}_{\mathrm{x}}\right) \mathrm{Ba}_{2} \mathrm{Ca}_{n-1} \mathrm{Cu}_{n} \mathrm{O}_{2 n+2}$. These superconductors are prepared at normal pressure by substituting thallium at copper site in $\mathrm{Cu}_{m} \mathrm{Ba}_{2} \mathrm{Ca}_{n-l} \mathrm{Cu}_{n} \mathrm{O}_{2 n+2}$ superconductors. These superconductors have anisotropy parameter $(\gamma=3-11)$ in between that of $\mathrm{Cu}$ and $\mathrm{Tl}$ based superconductors. In this article we have first reviewed the methods of preparation and physical properties of thallium based superconductors and then the copper based superconductor. We have also shown that the Tl-1223 as well $\mathrm{Cu}-1223$ superconductors is more promising members of their families. At the end the end of the article the superconducting properties of $\left(\mathrm{Cu}_{1-\mathrm{x}} \mathrm{Tl}_{\mathrm{x}}\right) \mathrm{Ba}_{2} \mathrm{Ca}_{2} \mathrm{Cu}_{3} \mathrm{O}_{10-\delta}$ are given.

\section{Thallium Based Superconductors}

The thallium based Tl-Ba-Ca-Cu-O (TBCCO) superconductor was discovered in 1988 by Sheng and Hermann $[1,2-6]$ which is proven to be the best among all other cuprates due to their higher transition temperature, $\left[\mathrm{T}_{\mathrm{c}}(0)\right]$, transport critical current densities, $\left[\mathrm{J}_{\mathrm{c}}\right]$ and low microwave surface resistances, $\left[R_{s}\right]$. Since the discovery of superconductivity in this system, several new phases of $\mathrm{Tl}_{m} \mathrm{Ba}_{2} \mathrm{Ca}_{n-1} \mathrm{Cu}_{n} \mathrm{O}_{2 n+2}(m=1,2 ; n=1,2,3,4,5)$ have been synthesized $[7,8-10]$. In the two-layer thallium compounds, the $\mathrm{Tl}_{2} \mathrm{Ba}_{2} \mathrm{Cu}_{1} \mathrm{O}_{6}, \mathrm{Tl}_{2} \mathrm{Ba}_{2} \mathrm{Ca}_{1} \mathrm{Cu}_{2} \mathrm{O}_{8}, \mathrm{Tl}_{2} \mathrm{Ba}_{2}$ $\mathrm{Ca}_{2} \mathrm{Cu}_{3} \mathrm{O}_{10}, \mathrm{Tl}_{2} \mathrm{Ba}_{2} \mathrm{Ca}_{3} \mathrm{Cu}_{4} \mathrm{O}_{10}$, and $\mathrm{Tl}_{2} \mathrm{Ba}_{2} \mathrm{Ca}_{4} \mathrm{Cu}_{5} \mathrm{O}_{8}$ are major phases, which can be simply represented as, Tl-2201, Tl-2212, Tl-2223, Tl-2224 and Tl-2245 with critical temperatures of $95,118,127,112$ and $105 \mathrm{~K}$ respectively. The maximum critical temperature of $\sim 127 \mathrm{~K}$ is found in Tl-2223 superconductor $[11,12]$. On the other hand the monolayer Tl-based system includes $\mathrm{TlBa}_{2} \mathrm{Ca}_{1} \mathrm{Cu}_{2} \mathrm{O}_{7}$, 
$\mathrm{Tl}_{1} \mathrm{Ba}_{2} \mathrm{Ca}_{2} \mathrm{Cu}_{3} \mathrm{O}_{9}, \mathrm{TlBa}_{2} \mathrm{Ca}_{3} \mathrm{Cu}_{4} \mathrm{O}_{11}$, and $\mathrm{Tl} \mathrm{Ba}_{2} \mathrm{Ca}_{4} \mathrm{Cu}_{5} \mathrm{O}_{13}$ superconductor phases, which for brevity can be represented as Tl-1212, Tl-1223, Tl-1234 and Tl-1245 with critical temperatures 103, 123, 112 and $107 \mathrm{~K}$ respectively. The materials with double Tl-O layers have body centered tetragonal structure and single Tl-O layer compounds have primitive tetragonal structure. The crystal structures of Tl-2223 and Tl-1223 superconductors are shown in Figure 1. A brief review of thallium-based superconductors will be given in the following sections.

\section{1 $\mathrm{Tl}_{2} \mathrm{Ba}_{2} \mathrm{Ca}_{n-1} \mathrm{Cu}_{n} \mathrm{O}_{2 n+2}$ Superconductors}

The thallium-based compounds with double Tl-O layer in the unit cell are the best among other cuprates of LBCO, YBCO and BSCCO series due to their higher critical temperature and low microwave surface resistance. These materials exhibit tetragonal symmetry with $\mathrm{I} / \mathrm{mmm}$ space group. The structure of these compounds comprises copper provskite-like blocks with $n(n=1,2,3 \ldots) \mathrm{CuO}_{2}$ planes separated by two Tl-O layers. Each $\mathrm{CaO}$ layer is sandwiched between two $\mathrm{CuO}_{2}$ planes and $\mathrm{BaO}$ layer between the $\mathrm{CuO}_{2}$ plane and $\mathrm{TlO}$ layers. These compounds can be represented by a formula Tl-22 $(n 1) n$, where $n$ represents the number of $\mathrm{CuO}_{2}$ planes. The oxygen coordination number of $\mathrm{Tl}, \mathrm{Cu}, \mathrm{Ca}$ and $\mathrm{Ba}$ in these compounds is $6,4 / 5,8$, and 9 respectively. The c-axis lengths in these materials ranges from $23.248 \AA$ for $n=1$ to $42.07 \AA$ for $n=4[13,14]$. The critical temperature

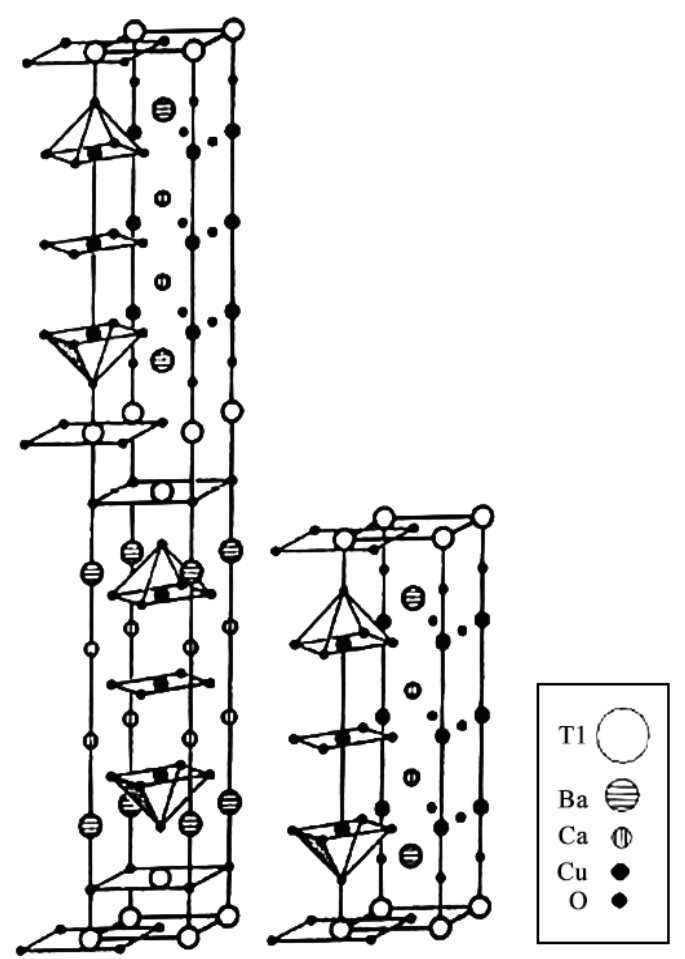

Figure 1. The crystal structures of Tl-2223 and Tl-1223 superconductor increases up to $127 \mathrm{~K}$ with number of $\mathrm{CuO}_{2}$ planes $n$ from 1 to 3 and then decreases for higher number of $\mathrm{CuO}_{2}$ planes in the unit cell of bilayer $\mathrm{TlO}$ compounds. In Figure 2 is shown the dependence of $\mathrm{T}_{\mathrm{c}}$ on number of $\mathrm{CuO}_{2}$ planes for different superconductors. Since Tl-based superconductor materials have higher critical temperature, so much attention has been given to the synthesis of bulk and thin film samples of these compounds, which can be used for electronic devices [15-24]. Among the double TlO layer compounds, the Tl-2223 is the most promising due to its high critical temperature of $127 \mathrm{~K}$ as compared to its counterparts in double Tl-O layer series $[25,26]$. Both the bulk and thin film samples of this material have been prepared [22]. The superconducting properties of Tl-22(n-1)n compounds can be changed by employing different synthesis routes and doping of different cations (i.e. $\mathrm{Hg}, \mathrm{Pb}, \mathrm{Sr}, \mathrm{Y}, \mathrm{Pr}$, Co etc. ) in charge reservoir block and superconducting block [23,27-37]. Parkin et al. have been succeeded to prepare $\mathrm{Tl}_{2} \mathrm{Ba}_{2} \mathrm{Ca}_{2} \mathrm{Cu}_{3} \mathrm{O}_{\mathrm{x}}$ superconductor with critical temperature, which varies from 118 to $127 \mathrm{~K}$ depending upon the synthesis conditions [8]. The substitution of $\mathrm{Hg}$ at thallium site has been seen to improve the staking regularity of the atomic layers in the 2223 phase and phase stability as compared to pure Tl-2223 phase [38-40]. The critical

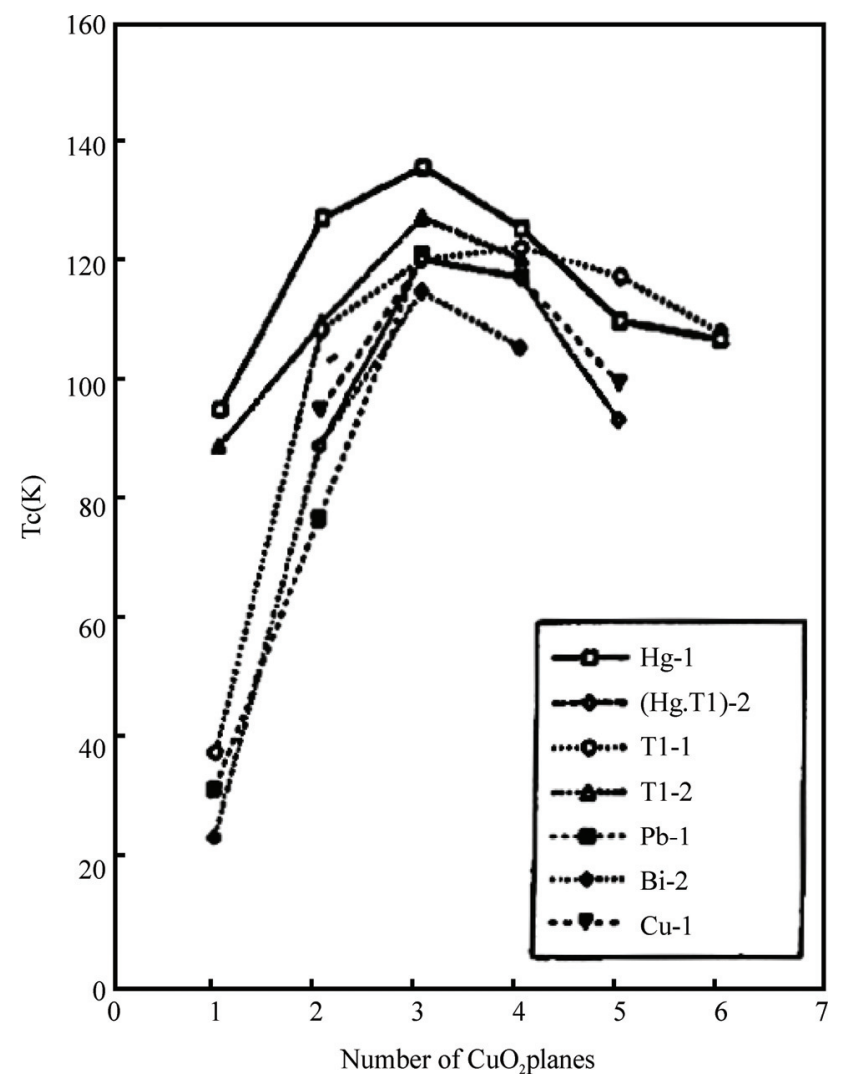

Figure 2. The dependence of critical temperature on number of $\mathrm{CuO}_{2}$ planes in different superconductors [64] 
temperature, however, decreases in $\mathrm{TlHg}-2223$ to $118 \mathrm{~K}$ but in $\mathrm{TlHg}-2212$ the $\mathrm{T}_{\mathrm{c}}(0)$ has been raised to $5 \mathrm{~K}$ higher than pure thallium based superconductor [23]. In Tl-2212 superconductors the doping of tetravalent $\mathrm{Pr}$ at $\mathrm{Ca}$ site was found to suppress the superconductivity [31]. Two reasons are proposed for the suppression of superconductivity with Pr substitution. One is the breaking of cooper pairs due to their interaction with magnetic moment of $4 f$ electrons of Pr ion and secondly, the localization of carriers caused by the overlap of $4 f$ orbital with $\mathrm{O} 2 \mathrm{p}-\mathrm{Cu} 3 \mathrm{~d}$ orbital. On the other hand the Y at Ca site in Tl-2212 superconductor has the same effect like that of Pr, suppressing the critical temperature and localization of carriers but in a different manner because $\mathrm{Y}$ does not have $4 f$ electrons [41]. The decrease in the $\mathrm{T}_{\mathrm{c}}(0)$ of Tl-2212 superconductor with Pr concentration is shown in Figure 3. Similarly the doping of magnetic impurities at $\mathrm{Cu}$ site in $\mathrm{CuO}_{2}$ planes can also suppress the superconductivity due to scattering of superconducting carriers from these impurity atoms. In Tl-2212 the cobalt substitution at $\mathrm{Cu}$ site has shown decrease in the critical temperature with increased Co concentrations [34]. The phase purity is necessary for the use of superconducting compounds for device fabrications. The partial substitution of $\mathrm{Ba}$ by $\mathrm{Sr}$ in thallium-based superconductors can improve their phase stability. The doping of $\mathrm{Sr}$ at $\mathrm{Ba}$ in Tl-2223 superconductor resulted in a phase pure material, but with a lower $\mathrm{T}_{\mathrm{c}}(0)$ as compared to $\mathrm{Sr}$ free compound [30]. The addition of $\mathrm{Ag}_{2} \mathrm{O}$ in the starting composition also stabilizes Tl-2223 phase otherwise the chances of formation of Tl-2212 superconductor with two $\mathrm{CuO}_{2}$ layers are increased [22]. In addition to the phase stability the addition of silver can improve the intergranular coupling, which enhances the transport properties such as critical current density and decreases the room temperature resistivity $[22,39,40]$. The critical current density with $\operatorname{Ag}_{2} \mathrm{O}$ doped Tl-2223 samples is estimated to be three times the critical current of undoped material [22]. Figure 4 shows the results of $\mathrm{T}_{\mathrm{c}}(0)$ and $\mathrm{R}(300 \mathrm{~K})$ for different

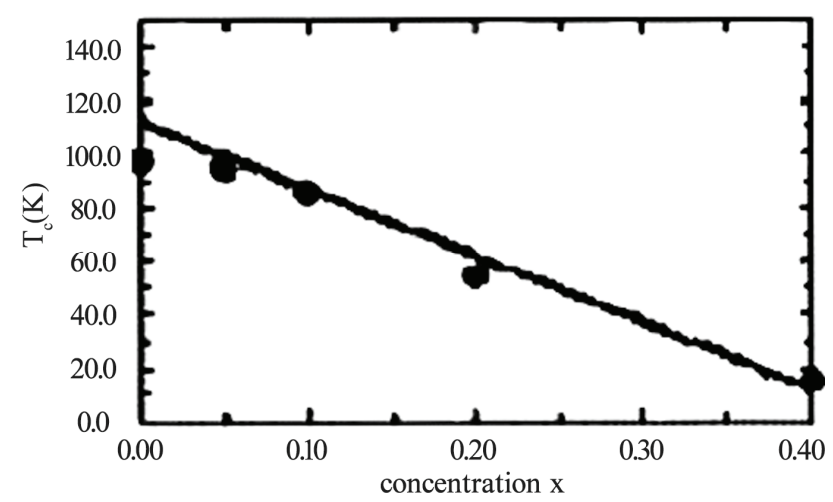

Figure 3. The lowering of critical temperature in Tl-2212 superconductor with the increase of $\operatorname{Pr}$ concentration [31]

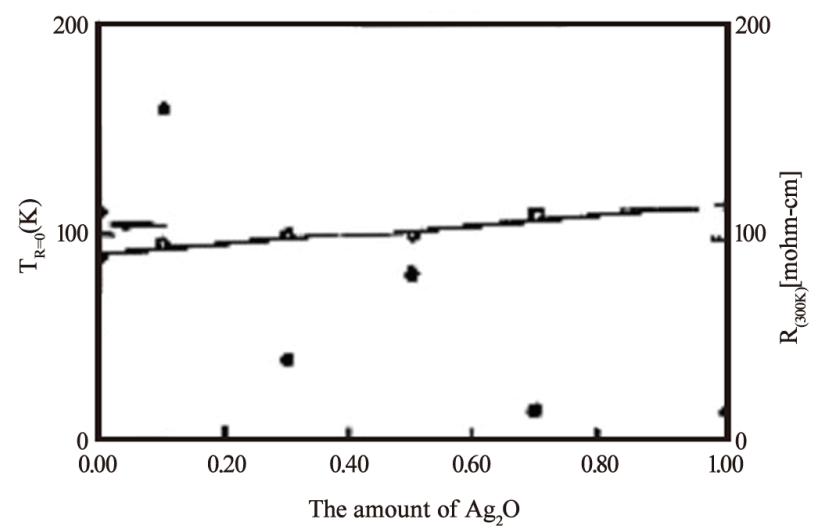

Figure 4. Variation of critical temperature and room temperature resistivity with $\mathrm{Ag}_{2} \mathrm{O}$ concentration in $\mathrm{Tl}-2223$ superconductor [22]

$\mathrm{Ag}_{2} \mathrm{O}$ doping concentrations. The doping of $\mathrm{Li}$ in $\mathrm{Tl}-$ 2223 starting composition results in a critical temperature of $117 \mathrm{~K}$ and the normal state resistivity becomes independent of the applied magnetic fields [29]. Since the maximum $\mathrm{T}_{c}(0)$ in a given compound also strongly depends on the interlayer coupling so the external pressure can be used as a source to improve the superconducting properties intrinsically. The application of pressure contracts the $\mathrm{Cu}$-(apical) oxygen bond length which favors the transfer of carriers from the charge reservoir layer to $\mathrm{CuO}_{2}$ planes. D. Tristan et al. have studied the properties of Tl-2223 and Tl-2234 superconductors under different pressures and found that the critical temperature $(\sim 119 \mathrm{~K})$ of Tl-2223 sample prepared under ambient pressure is increased to $133 \mathrm{~K}$ when $4.2 \mathrm{GPa}$ pressure was applied [25]. The change in the critical temperature of Tl-2223 and Tl-2234 with applied pressure is shown in Figure 5. The reliable, high quality thin films are prerequisite for the use of thallium based high temperature superconductors for electrical, magnetic and optical applications. The methods of preparation of thin films include $\mathrm{rf}$ and $\mathrm{dc}$ sputtering, sequential electron beam and thermal evaporation, and pulsed laser ablation. The highest critical current density in double layer $\mathrm{TlO}$ compounds is attained in Tl-2223 thin films, which is of the order of $107 \mathrm{~A} / \mathrm{cm}^{2}$ $(90 \mathrm{~K}, 0 \mathrm{~T})$ [5]. On the other hand the critical current density of Tl-2212 superconductor is in the range of $10^{5}-10^{6}$ $\mathrm{A} / \mathrm{cm}^{2}$ at $77 \mathrm{~K}$ depending upon the deposition techniques used [42-46].

\section{2 $\mathrm{Tl}_{1} \mathrm{Ba}_{2} \mathrm{Ca}_{n-1} \mathrm{Cu}_{n} \mathrm{O}_{2 n+2}$ Superconductors}

The family of thallium based superconductors with single Tl-O layer is comprised of Tl-1212, Tl-1223 and Tl-1234 compounds. These superconducting compounds are more promising because of their lower anisotropy, higher $\mathrm{T}_{\mathrm{c}}(0)$, higher critical current densities and irreversibility field $\mathrm{H}_{\text {irr }}$ as compared to their counterparts in double Tl-O 

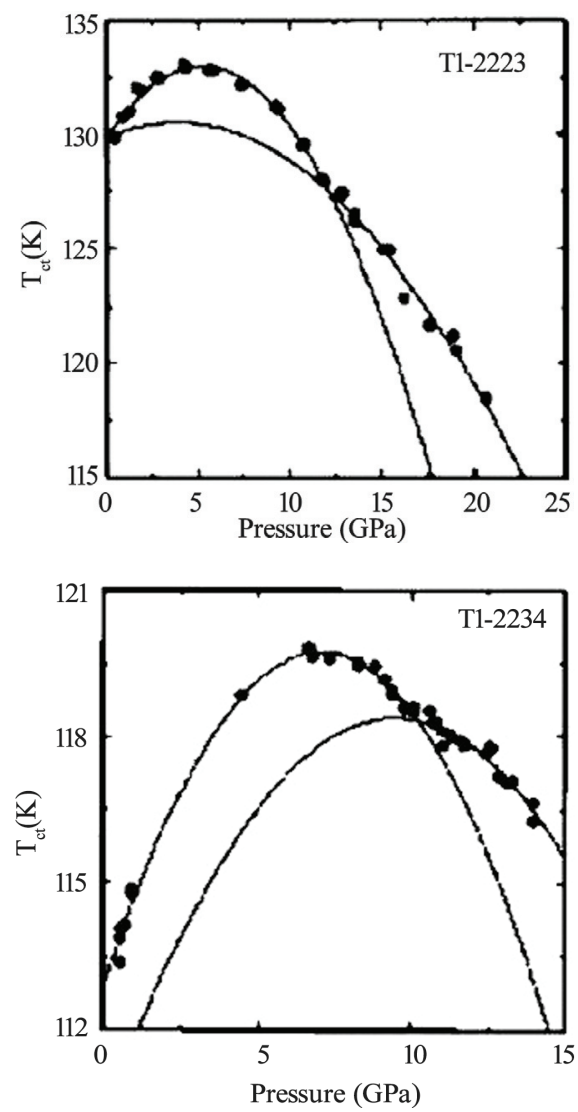

Figure 5. Effect of pressure on critical temperature of Tl-2223 and Tl-2234 superconductor [25]

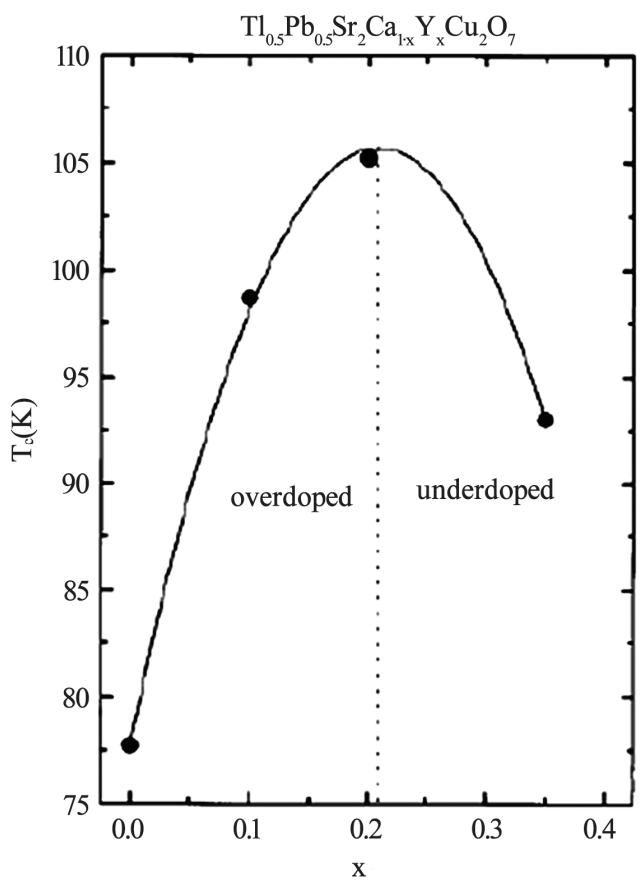

Figure 6. The $T_{c}(0)$ versus doping concentration of $Y$ in $T I P b-$ 1212 superconductor $[56]$

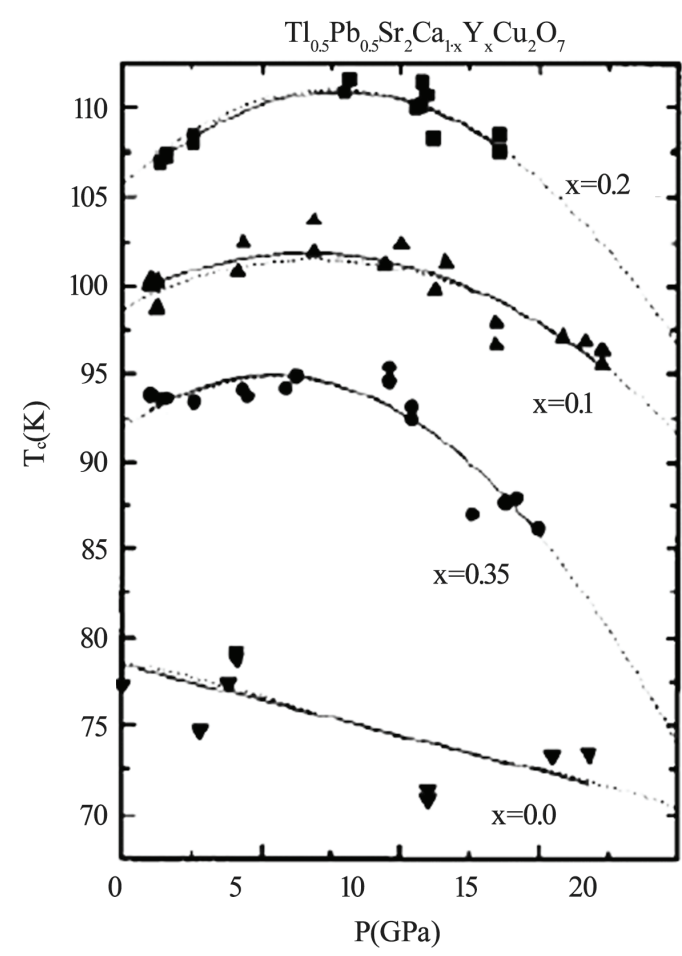

Figure 7.The variation of critical temperature with applied pressure for different concentrations of $\mathrm{Y}$ in TIPb-1212 superconductor [56]

layer superconductors family [47-55]. The $\mathrm{TlSr}_{2} \mathrm{CaCu}_{2}$ $\mathrm{O}_{7}$ (Tl-1212) is the parent compound in single $\mathrm{Tl}-\mathrm{O}$ layer superconductors showing no signs of superconductivity down to liquid helium temperature because it grows in the over-doped state [56]. But the substitutions at $\mathrm{Tl}$ and $\mathrm{Ca}$ sites have been proven to bring about the superconductivity in this compound and enhance its phase stability [57-60]. When doped with $\mathrm{Pb}$ or $\mathrm{Cr}$ at the thallium site and $\mathrm{Y}$ at the $\mathrm{Ca}$ site the critical temperature has been enhanced to $110 \mathrm{~K}$ in Tl-1212 [57,58,61]. But the Pr or Nd substitution at the Ca site lowers the $T_{c}(0)$ of this material because the number of holes are reduced below the optimum value; these elements promote the hole filling mechanism [61]. The application of pressure can also optimize the number of holes in $\mathrm{CuO}_{2}$ planes and increases the critical temperature. In Figures 6 and 7, the dependence of critical temperature of $\mathrm{TlPb}-1212$ superconductor (doped with $\mathrm{Y}$ ) on the doping concentration and the applied pressure is shown. The Tl-1212 superconductor has lower anisotropy due to short insulating distance between $\mathrm{CuO}_{2}$ planes and exhibit higher critical current density [54]. The thin films prepared by this material has $\mathrm{J}_{\mathrm{c}}(77 \mathrm{~K}, 0 \mathrm{~T})$ in the range of $10^{6}-10^{7} \mathrm{~A} / \mathrm{cm}^{2}$ $[54,62]$. Although these materials can be used for application due to their low anisotropy but these are not ideal due to their lower $T_{c}(0)$ as compared to other members of this homologous series. It is observed in monolayer thal- 
lium based compounds that the critical temperature depends on the number of $\mathrm{CuO}_{2}$ planes. As the number of $\mathrm{CuO}_{2}$ planes increases from $n=3$ to either $n=4$ or 5 , the $\mathrm{T}_{\mathrm{c}}(0)$ decreases because in $n>3$ phases there are inequivalent $\mathrm{CuO}_{2}$ planes in which holes are inhomogeneously distributed which results in a lowering of critical temperature, Figure $2[63,64]$. Among the $\mathrm{Tl}_{1} \mathrm{Ba}_{2} \mathrm{Ca}_{n-1} \mathrm{Cu}_{n}$ $\mathrm{O}_{2 n+2}$ superconductors family the $n=3$ member is important due to its higher critical temperature, excellent fluxpinning properties, higher critical current and irreversibility field $\mathrm{H}_{\text {irr }}$ [65-70]. The Tl-1223 was the first superconducting composition reported among the other members of this family [71]. The single-phase samples of Tl-1223 are difficult to prepare. The researchers have adopted different synthesis routes to achieve a phase pure material. One way of improving the phase purity of Tl1223 compound is the substitution of $\mathrm{Pb}$ and (or) $\mathrm{Bi}$ for $\mathrm{Tl}$, and $\mathrm{Sr}$ for $\mathrm{Ba}$ in the starting composition [69,72-77]. The addition of $\mathrm{Pb}$ and the variation in the $\mathrm{Ca} / \mathrm{Sr}$ ratio is not only helpful in stabilizing the Tl-1223 phase but also results in higher critical temperature $\left(T_{c}>120 K\right)$, high $J_{c}$, $\mathrm{H}_{\text {irr }}$ field and strong flux pinning properties at $77 \mathrm{~K}$ $[52,68,78-81,82]$. The critical current density in $\mathrm{Pb}$ and $\mathrm{Sr}$ substituted sample is of the order of 103-105 A/cm $[55,70]$. The complete replacement of $\mathrm{Ba}$ by $\mathrm{Sr}$ lowers the transition temperature of Tl-1223 superconductors [83]. In the preparation of Tl-1223 compounds it is found that a starting composition deficient in thallium produces the highest percentage of Tl-1223 phase [8]. The high vapor pressure of $\mathrm{Tl}_{2} \mathrm{O}_{3}$ at synthesis temperatures also hinders the formation of Tl-1223 superconductors [84,85]. This problem can be overcome by employing the two zone processing technique in which independent control of partial pressure of $\mathrm{Tl}_{2} \mathrm{O}_{3}$, oxygen gas, sample temperature and composition could be varied $[68,85,86]$. The use of high-pressure synthesis technique is also helpful in achieving single phase of Tl-1223 superconductors with out any cationic substitutions [87,88]. In addition T1-1223 samples prepared under high pressure have shown increase in the critical temperature, transport $\mathrm{J}_{\mathrm{c}}$, and high irreversibility field $\mathrm{H}_{\text {irr }}$, Figure 8 [77,89]. The application of pressure improves the intergranular coupling and facilitates charge transport process, which results in higher $\mathrm{J}_{\mathrm{c}}$ and $\mathrm{H}_{\text {irr. }}$. A factor, which can suppress the phase stability and superconductivity in Tl-1223, is the presence of carbon in the starting composition $[51,88,90]$. The carbon may go to the $\mathrm{Tl}$ site in the unit cell and as a result decreases the number of holes in $\mathrm{CuO}_{2}$ planes and lowers the critical temperature [88], therefore, it is necessary to minimize the carbon content in the precursor powders. The carbon can also form non-superconductor phases in the form of carbonates of $\mathrm{Ba}$ and/or Ca. Figure 9 shows the lowering of the critical temperature of Tl-1223 superconductor with enhanced concentration of carbon in the starting composition. The use of $\mathrm{TlF}$ instead of $\mathrm{Tl}_{2} \mathrm{O}_{3}$

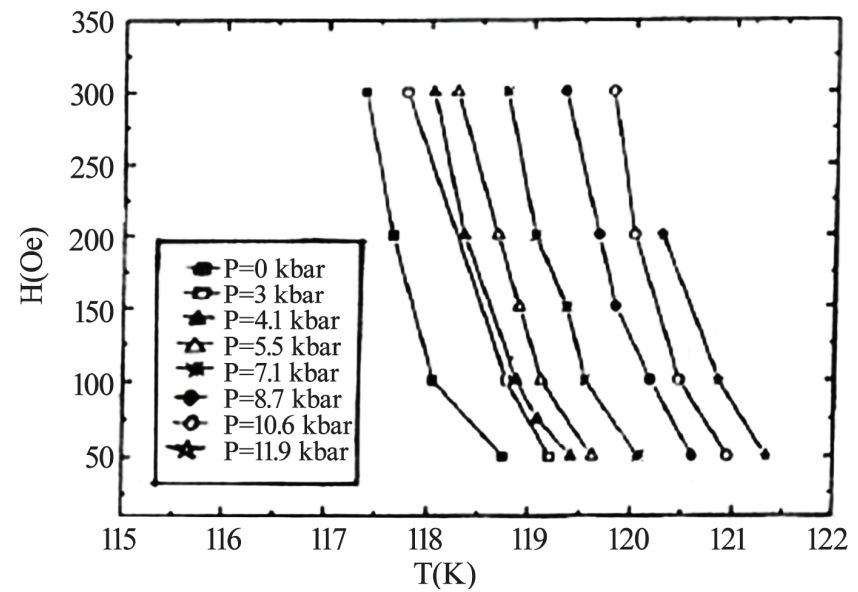

Figure 8. The shifting of irreversibility line of Tl-1223 superconductor to higher temperatures with the increased pressure [89]

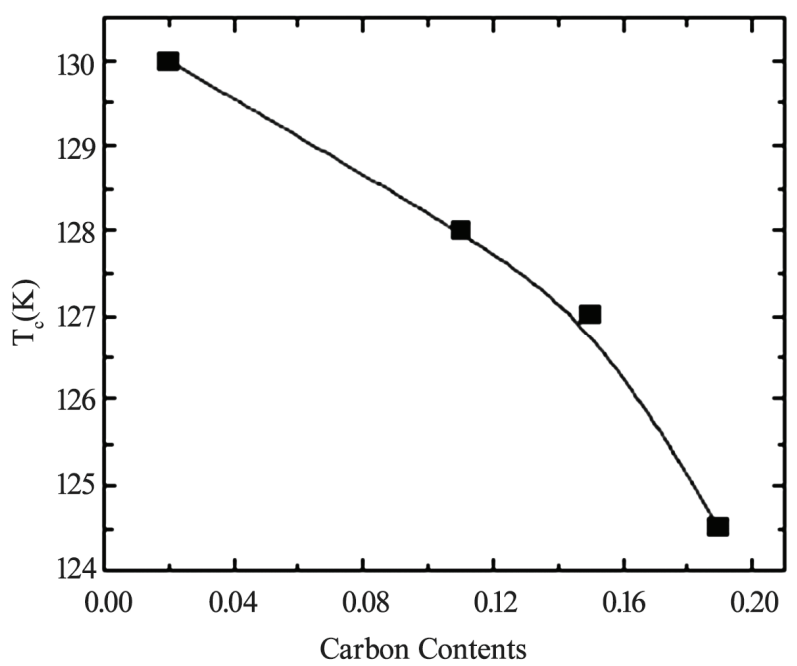

Figure 9. The decrease in critical temperature of Tl-1223 superconductor with increased carbon contents in starting composition [88]

in the starting composition of Tl-1223 enhances the formation of single phase Tl-1223 material with out any $\mathrm{Pb}$ or Srdoping and increases $\mathrm{J}_{\mathrm{c}}(77 \mathrm{~K}, 0 \mathrm{~T})$ and irreversibility field $\mathrm{H}_{\text {irr }}[90,91]$. The thin films of Tl-1223 prepared by using $\mathrm{TlF}$ are found to have critical current density of $4.4 \times 10^{6} \mathrm{~A} / \mathrm{cm}^{2}$ at $77 \mathrm{~K}$ in zero field [84]. Since the ionic radius of fluorine $\left[\mathrm{F}_{-1}(1.36 \AA)\right]$ is comparable to that of oxygen $\left[\mathrm{O}^{-2}(1.4 \AA)\right]$ so fluorine most probably occupies the oxygen lattice site in the unit cell [92]. The holes concentration in the $\mathrm{CuO}_{2}$ planes decreases when fluorine replaces oxygen in the Tl-1223 superconductor because of the more electronegative nature of $\mathrm{F}$ ion as compared to oxygen [93]. The carrier concentration approaches optimum level and $\mathrm{T}_{\mathrm{c}}(0)$ is increased. In $\mathrm{Tl}(\mathrm{Pb}) \mathrm{Ba}(\mathrm{Sr}) \mathrm{Ca}$ $\mathrm{CuOF}_{\mathrm{x}}$ composition, the critical temperature has been 
enhanced with fluorine contents up to $\mathrm{x}=1$ and a pure Tl-1223 phase with highest $J_{c}$ was achieved with $x=3$ [85]. The samples of TBCCO (T1-1223) superconductors with more than $95 \%$ purity can also be obtained by choosing the appropriate synthesis temperature and controlling the reaction time with out any substitutions [94]. Although most of the substitutions in Tl-1223 superconductors were made to improve the phase stability of these compounds but these doping can also control the carrier concentration and in turn the superconducting properties of these compounds. The rare earth cations (La, Sm, Pr, $\mathrm{Eu})$ substitutions at the Ca sites in Tl-1223 superconductors have been found to lower the critical temperature and the phase stability of this compound [95-99]. But when one of the rare earth elements $\mathrm{Ce}$ was doped at $\mathrm{Sr}$ site the critical temperature was increased from $92 \mathrm{~K}$ to $98 \mathrm{~K}$ with the increased concentration of cerium. The increase in $\mathrm{T}_{\mathrm{c}}(0)$ was attributed to the improved coupling between the $\mathrm{CuO}_{2}$ planes due to the decreased c-axis length [100]. The critical temperature and the critical current density of Tl-1223 superconductor decreases with low level doping concentration of $3 \mathrm{~d}$ transition metals $\mathrm{Co}, \mathrm{Zn}, \mathrm{Fe}$ and $\mathrm{Ni}$ at $\mathrm{Cu}$ site and superconductivity disappears for higher concentrations of these elements [101-104]. The presence of these ions in $\mathrm{CuO}_{2}$ planes acts as scattering centers, which resulted in the Cooper pair breaking, and destroys the superconducting state in Tl-1223 compounds. When the transition metal ions are substituted at the $\mathrm{Tl}$ site in the charge reservoir layer of Tl-1223 superconductor the critical temperature was decreased following the same mechanism mentioned earlier [105]. The thin films of thallium based superconductors are of interest for electronic devices due to their higher $\mathrm{T}_{\mathrm{c}}(0)$ and low surface resistance $R_{s}$ [106]. Among the thallium-based compounds the thin films of single $\mathrm{TlO}$ layer materials (T1-1223) are superior because of their higher $T_{c}(0)$ and $\mathrm{J}_{\mathrm{c}}$ [107]. Thin films of Tl-1223 superconductors have critical current density in the range of $10^{5}-10^{6} \mathrm{~A} / \mathrm{cm}^{2}$ at $77 \mathrm{~K}$ (both in field cooled and zero field cooled samples) depending upon the deposition technique adopted [47,66,84,107-109].

\section{Why Tl-1223 Superconductor is Superior}

The Tl-based high $T_{c}$ cuprates exhibit layered structure which consists of intergrowths along c-axis containing $\mathrm{CuO}_{2}$ planes and rock salt type layers containing $\mathrm{Tl}$ cations. The insulating Tl-O layers separate the $\mathrm{CuO}_{2}$ blocks in the crystal. The $\mathrm{CuO}_{2}$ planes are found to be more favorable for superconductivity as compared to insulating charge reservoir block containing single or double Tl-O layers [110]. The superconducting properties like critical temperature, irreversibility field, critical current density and flux pinning in thallium-based compounds largely depend on the thickness of the insulating
T1-O layer and the strength of Josephson coupling between $\mathrm{CuO}_{2}$ planes $[23,49,50,53,111-115]$. The presence of the Tl-O layers between the $\mathrm{CuO}_{2}$ superconducting blocks yields anisotropy in the physical properties of these compounds. The anisotropy parameter is defined by $\gamma=\xi_{\mathrm{ab}} / \xi_{\mathrm{c}}, \gamma=\rho_{\mathrm{c}} / \rho_{\mathrm{ab}}$ or is the ratio of the effective carrier mass in the superconducting state. The anisotropy in these superconductors results in a shorter coherence length of cooper pairs along $\mathrm{c}$ direction as compared to the spacing between the $\mathrm{CuO}_{2}$ layers which can reduce the critical current density and irreversibility field of these materials. The anisotropy parameter depends on the thickness of the insulating charge reservoir layer and the spacing between the individual $\mathrm{CuO}_{2}$ planes, the Tlbased compounds with double Tl-O layers in the structure have large anisotropy as compared to the compounds with single Tl-O layer ( $\gamma=17$ for (TlBi)-1212 and $\gamma=104$ for T1-2212). The higher anisotropy degrades the superconducting properties in terms of lower technological critical temperature, $\mathrm{Z}=\mathrm{T}_{\mathrm{c}} / \gamma^{1 / 2}$, critical current density $\mathrm{J}_{\mathrm{c}}$ and irreversibility field, $\mathrm{H}_{\text {irr }}$. The $\mathrm{H}_{\text {irr }}$ is an important physical quantity that characterizes a superconductor for its use in magnetic fields. The irreversibility field largely depends on the inter layer coupling strength [110].

$$
\mathrm{H}_{\mathrm{irr}} \propto 1 / \rho_{\mathrm{c}} \times \mathrm{d}_{\mathrm{c}}
$$

where $d_{c}$ is the repeat distance of the structure along $c$ direction and $\rho_{c} \propto \exp \left(d_{i} / d_{o}\right) d_{i}$ is the thickness of the insulating layer and do is the characteristic thickness of the material. The exponential dependence of $\mathrm{H}_{\text {irr }}$ on $\mathrm{d}_{\mathrm{i}}$ shows that superconducting materials with large insulating spacing exhibit low irreversibility filed than the materials with smaller insulating spacing [53,116,117]. The irreversibility field ' $\mathrm{H}_{\text {irr }}$ ' of Tl-1223 superconductor follows the sequence; $\mathrm{H}_{\text {irr }}(\mathrm{Tl}-1223)>\mathrm{H}_{\text {irr }}(\mathrm{Tl}-2223 / \mathrm{Tl}-2212)>$ $\mathrm{H}_{\text {irr }}(\mathrm{Bi}-2212)$ [116,117]. Figure 10 shows the comparison of irreversibility line of Tl-1223 and Tl-2223 superconductors and in Figure 11 the dependence of $\mathrm{H}_{\text {irr }}$ on the thickness of the unit cell along c-axis for different Tl-based compounds is shown. A higher irreversibility line is observed for Tl-1223 due to its lower anisotropy.



Figure 10. Comparison of irreversibility line of Tl-2223 and Tl-1223 superconductor [53] 


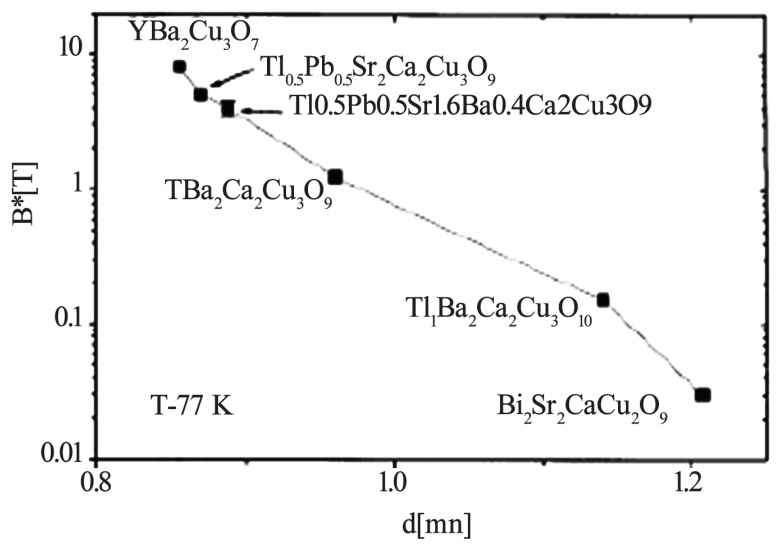

Figure 11. The irreversibility field versus thickness of charge reservoir block [52]

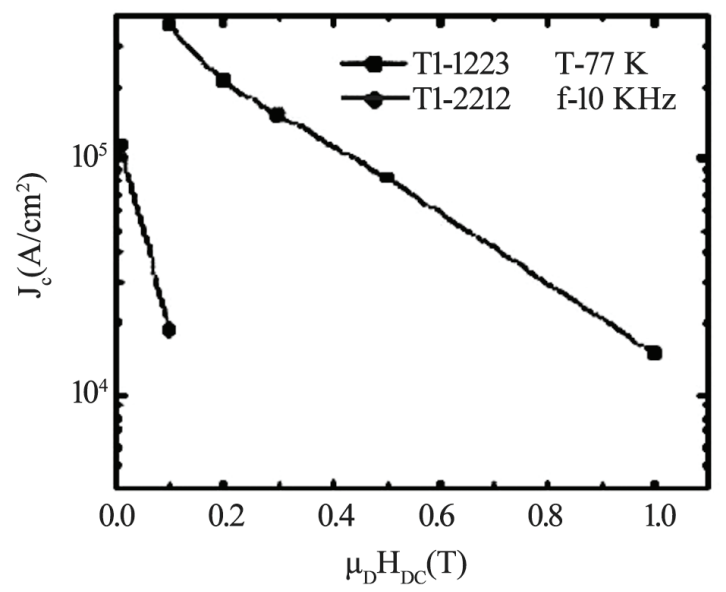

Figure 12. Dependence of critical current density of Tl-1223 and Tl-2212 superconductors on applied magnetic field [47]

The measured anisotropy parameter $\gamma$ for Tl-1223 superconductors is 8 [53]. The interlayer coupling can also affect the critical current density of these superconductors. The Tl-1223 superconductors have been found to have higher $J_{c}$ as compared to Tl-2212 and Tl-2223 compounds $[47,49,50]$. The Tl-1223 superconductors are very useful in electronic devices fabrication because the critical currents in these compounds decreases slowly as compared to double Tl-O layer compounds in the presence of external magnetic fields [47,55]. In Figure 12, a comparison of the magnetic field dependence of $\mathrm{J}_{\mathrm{c}}(77 \mathrm{~K})$ of Tl-1223 and Tl-2212 is shown. The increase in the number of insulating layers in superconductors results in reduced Josephson coupling between conducting $\mathrm{CuO}_{2}$ planes along the c-axis, which decreases the critical current density. The reduced interlayer coupling in double Tl-O layer compounds results in a shorter coherence length of cooper pairs along c-axis and hence the inferior superconducting properties. The small distance between $\mathrm{Cu}-\mathrm{O}$ conducting planes may be the key to finding alter- natives for attaining high critical current densities. Therefore, much attention is being given to Tl-1223 superconductors because they offer stronger interlayer coupling along c direction [48]. The coupling between $\mathrm{CuO}_{2}$ planes of Tl-1223 compound can further be improved by replacing $\mathrm{Ba}$ by $\mathrm{Sr}$ and $\mathrm{Tl}$ by $\mathrm{Pb}$ or by the application of the external pressure which will be helpful in enhancing its superconducting properties $[25,76]$.

\section{4. $\mathrm{CuBa}_{2} \mathrm{Ca}_{n-1} \mathrm{Cu}_{n} \mathrm{O}_{2 n+4}$ Superconductors}

As the stronger coupling between $\mathrm{CuO}_{2}$ planes lowers the anisotropy in high temperature superconductors and in turn enhances their superconducting properties i.e. $T_{c}(0)$, $\mathrm{J}_{\mathrm{c}}$ and $\mathrm{H}_{\mathrm{irr}}$, any superconducting material having these properties will be very useful from application point of view. In the previous sections we have seen that the Tl1223 superconductor has least anisotropy and higher $T_{c}(0)$ among all members of single Tl-O layer compounds, but the toxicity of $\mathrm{Tl}$ hinders their use in wide verity of applications. Therefore, the search for a superconductor material with low anisotropy and higher critical temperature was not stopped. A new family of superconductor materials, $\mathrm{CuBa}_{2} \mathrm{Ca}_{n-1} \mathrm{Cu}_{n} \mathrm{O}_{2 n+2}(n=1,2,3 \ldots) \quad[\mathrm{Cu}-12(n-1) n]$ prepared under high pressure (4-6 GPa), is thought to be the most promising due to its higher critical temperature and critical current density [118-124]. The members of $\mathrm{Cu}-12(n-1) n$ family has the same tetragonal structure as Tl-12(n-1)n compounds have copper in their charge reservoir layer, $\mathrm{CuBa}_{2} \mathrm{O}_{n+\delta}$. Since copper is good conductor, therefore, the conducting charge reservoir layer of these compounds makes them least anisotropic as oppose to Tl-based superconductors. The members of Cu-based superconductors follow the formula $\mathrm{Cu}-12(n-1) n$ with $n$ denoting the number of conducting $\mathrm{CuO}_{2}$ planes; the higher number of $\mathrm{CuO}_{2}$ planes are thought to have higher $T_{c}(0)$ since the optimum valency of copper for higher critical temperature is suggested to be $\mathrm{z}=2.33$. The maximum increase of critical temperature is theoretically predicted for phase with $n=11$ [124]. The relationship between valence state $\mathrm{z}$ of copper and number of $\mathrm{CuO}_{2}$ layers follows following empirical rule $\mathrm{z}=2+4 /(n+1)$ Among all the superconducting phases in this family the highest critical temperature is achieved in a phase with $n=3$ phase, $\mathrm{Cu}-1223\left(\mathrm{~T}_{\mathrm{c}}(0) \sim 120 \mathrm{~K}\right)$; in four $\mathrm{CuO}_{2}$ plane Cu-based superconductor $(\mathrm{Cu}-1234) \mathrm{T}_{\mathrm{c}}(0)$ is around $18 \mathrm{~K}$. These two compounds have least anisotropy ( $\gamma=5$ and 1.6 respectively) and long coherence length along c-axis [123-126]. The high-pressure synthesis of these compounds is not economically viable but by introducing thallium (which acts as structure stabilizer and reaction rate accelerator) into the charge reservoir layer, the superconductor phases can easily be obtained by normal pressure synthesis. The substitution of $\mathrm{Tl}$ in $\mathrm{Cu}-12(n-1) n$ compounds results in emergence of a new subfamily $\mathrm{Cu}_{1-\mathrm{x}} \mathrm{Tl}_{\mathrm{x}}-12(n-1) n$ which is the close derivative of these compounds. These com- 
pounds are prepared under high as well as normal pressure and have superconducting properties very close to Cu-based compounds [124,127-130]. The members of this family have semi insulating charge reservoir layer $\mathrm{Cu}_{1-\mathrm{x}} \mathrm{Tl}_{\mathrm{x}} \mathrm{Ba}_{2} \mathrm{O}_{4 n-\delta}$ which slightly increases the anisotropy but their anisotropy remains lower than that of Tl-based compounds. A comparison of the anisotropy parameter and technological critical temperature for superconductors of different families is shown in Figure 13. The $\mathrm{Cu}_{1-\mathrm{x}} \mathrm{Tl}_{\mathrm{x}} \mathrm{Ba}_{2} \mathrm{Ca}_{2} \mathrm{Cu}_{3} \mathrm{O}_{10-\delta} \quad\left(\mathrm{Cu}_{1-\mathrm{x}} \mathrm{Tl}_{\mathrm{x}}-1223\right)$ superconductor of this family has higher critical temperature and critical current density [125]. This compound with anisotropy parameter $(\gamma=5)$ has $\mathrm{Cu}_{1-\mathrm{x}} \mathrm{Tl}_{\mathrm{x}} \mathrm{Ba}_{2} \mathrm{O}_{4-\delta}$ charge reservoir layer and three $\mathrm{CuO}_{2}$ planes [131]. The c-axis length of $\mathrm{Cu}_{1-\mathrm{x}} \mathrm{Tl}_{\mathrm{x}}-1223$ is $15.89 \AA$, which, lies between $14.79 \AA$ and 15.93 $\AA$ of $\mathrm{Cu}-1223$ and Tl-1223 superconductors [125]. The $\mathrm{Cu}_{1-\mathrm{x}} \mathrm{Tl}_{\mathrm{x}}-1223$ superconductor has been prepared both in the form of thin films and bulk samples [114133]. The thin films of this compound have critical current density of the order of $10^{7} \mathrm{~A} / \mathrm{cm}^{2}(77 \mathrm{~K}, 0 \mathrm{~T})$ and $105 \mathrm{~A} / \mathrm{cm}^{2}(77 \mathrm{~K}, 10 \mathrm{~T})$ [132]. The superconducting properties of $\mathrm{Cu}_{1-\mathrm{x}} \mathrm{Tl}_{\mathrm{x}}-1223$ can further be enhanced by post-annealing and substitution of different cations $[125,128,134-138]$. The $T_{c}(0)$ of this material increases by self-doping mechanism when post-annealed in nitrogen atmosphere. The self-doping mechanism is completed by the reduction of $\mathrm{Tl}^{+3}$ to $\mathrm{Tl}^{+1}$ via $\mathrm{Tl}^{+2}$, Figure 14 [139-141].

Since the superconductivity is brought about by the carriers in conducting $\mathrm{CuO}_{2}$ planes, therefore, the interplanar coupling plays an important role in bringing about the improved superconducting properties. One approach to enhance the interplaner correlation is to reduce the spacing between $\mathrm{CuO}_{2}$ planes by replacing $\mathrm{Ca}$ with smaller sized ion. Magnesium (Mg) or Beryllium (Be) ions due to their smaller ionic radii as compared to $\mathrm{Ca}$ seems to be effective in bringing about such improved coupling possible The substitution of $\mathrm{Mg}$ or $\mathrm{Be}$ ion at $\mathrm{Ca}$



Figure 13. Comparison of anisotropy and technological critical temperature of different superconductors [126]

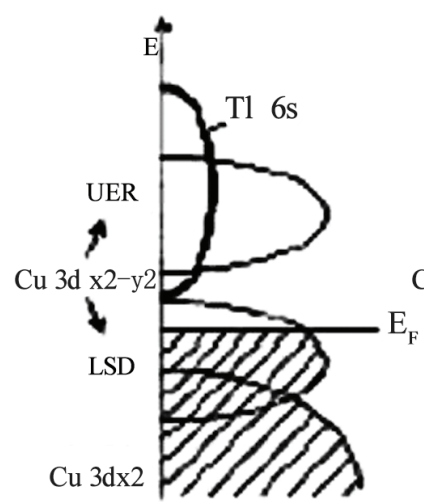

$\mathrm{T}^{+3}$

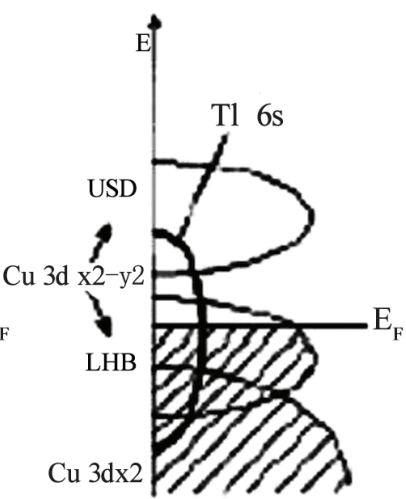

$\mathrm{T}^{+2}$
Figure 14. The energy level diagram of Tl6s level in $\mathrm{Cu}_{1-\mathrm{x}} \mathrm{Tl}_{\mathrm{x}}-1223$ superconductor before and after post-annealing in nitrogen [141]

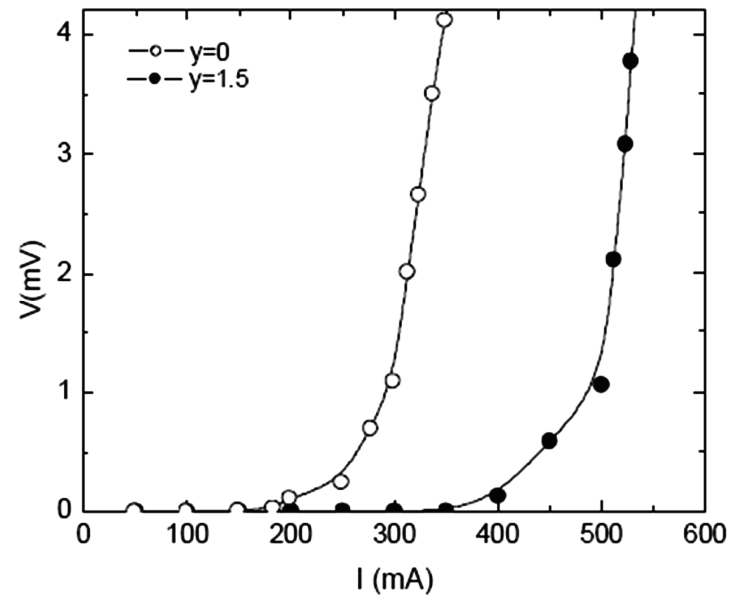

Figure 15. IV characteristics of $\mathrm{Cu}_{0.5} \mathrm{Tl}_{0.5} \mathrm{Ba}_{2} \mathrm{Ca}_{2-\mathrm{y}} \mathrm{Mg}_{\mathrm{y}} \mathrm{Cu}_{3} \mathrm{O}_{10-\delta}$ $(y=0,1.5)$ superconductor [142]

sites results in a material with highly correlated $\mathrm{CuO}_{2}$ planes. The Fermi wave vector $\left[\mathrm{k}_{\mathrm{F}}=\left(3 \pi^{2} \mathrm{~N} / \mathrm{V}\right)^{1 / 3}\right]$ depends on the volume of the unit cell therefore the decrease of the volume of unit cell with $\mathrm{Mg} / \mathrm{Be}$ substitution increases $\mathrm{k}_{\mathrm{F}}$. The coherence length along $\mathrm{c}$-axis $\left[\xi_{\mathrm{c}}=\hbar \mathrm{k}_{\mathrm{F}} / m 2 \Delta\right]$ is also increased, which decreases the anisotropy of the final compound [134-138]. The superconducting properties are improved $\left(\mathrm{T}_{\mathrm{c}}(0)\right.$ and $\mathrm{J}_{\mathrm{c}}(\mathrm{H}=0)$ increases) by substituting $\mathrm{Mg}$ or $\mathrm{Be}$ at $\mathrm{Ca}$ site in $\mathrm{Cu}_{1-\mathrm{x}} \mathrm{Tl}_{\mathrm{x}}-1223$. Figure 15 shows the increase of critical current of $\mathrm{Cu}_{1-\mathrm{x}} \mathrm{Tl}_{\mathrm{x}}-1223$ superconductor prepared at normal pressure by substituting $\mathrm{Mg}$ at $\mathrm{Ca}$ site; it has also enhanced the intergrain coupling witnessed from AC susceptibility measurements [142]. The variation of peak temperature $T_{P}$ with applied DC magnetic field in $\chi^{\prime /}$ part of AC susceptibility shows an enhanced inter-grain coupling, Figure 16. On the other hand when $\mathrm{Nb}$ with higher electronegativity as compared to $\mathrm{Mg}$ and $\mathrm{Be}$ is substituted in $\mathrm{Cu}_{1-\mathrm{x}} \mathrm{Tl}_{\mathrm{x}}-1223$ superconductor at $\mathrm{Ca}$ site the $\mathrm{T}_{\mathrm{c}}(0)$ first increases and then de- 
creases with the increase of $\mathrm{Nb}$ content. Similarly a decrease in magnitude of diamagnetism is observed with the increase of $\mathrm{Nb}$ concentration, Figure 17. The source of decrease in diamagnetism is the decreased density of carriers in conducting $\mathrm{CuO}_{2}$ planes [143]. But when $\mathrm{Pr}$ is substituted at $\mathrm{Ca}$ sites the critical temperature decreases with the increased Pr contents. Since Pr has larger ionic radius oppose to $\mathrm{Ca}$, it reduces the overlap of the cooper pair wave function in the two $\mathrm{CuO}_{2}$ planes and therefore, reduces the interplaner coupling and increases anisotropy which results in lowering of $\mathrm{T}_{c}(0)$ [138]. There is another member of $\mathrm{Cu}-12(n-1) n$ family which has carbon instead of $\mathrm{Tl}$ in the charge reservoir layer. The $n=3$ member of this family $(\mathrm{Cu}, \mathrm{C})-1223$ has higher critical temperature and low anisotropy [144]. The critical temperature of this compound is $120 \mathrm{~K}$ and lattice parameters $\mathrm{a}=3.862 \AA$ and $\mathrm{c}=14.80 \AA$ which are comparable to that of $\mathrm{Cu}-1223 \mathrm{su}-$ perconductors [144,145]. But $(\mathrm{Cu}, \mathrm{C})-1223$ does not have

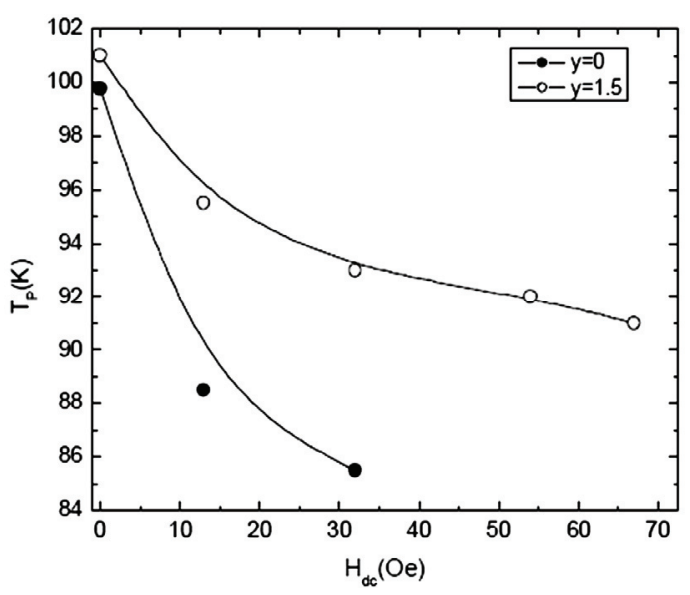

Figure 16. The peak temperature ' $T_{P}$ ' of $\mid / /$ versus $H_{d c}$ of $\mathrm{Cu}_{0.5} \mathrm{Tl}_{0.5} \mathrm{Ba}_{2} \mathrm{Ca}_{2-\mathrm{y}} \mathrm{Mg}_{\mathrm{y}} \mathrm{Cu}_{3} \mathrm{O}_{10-\delta}(\mathrm{y}=0,1.5)$ superconductor [142]

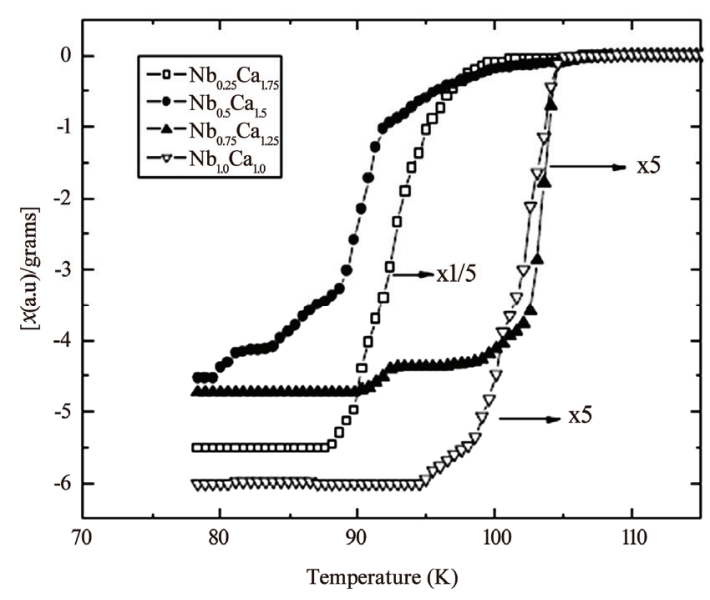

Figure 17. AC-susceptibility as a function of temperature of $\mathrm{Cu}_{0.5} \mathrm{Tl}_{0.5} \mathrm{Ba}_{2} \mathrm{Ca}_{2-\mathrm{y}} \mathrm{Nb}_{\mathrm{y}} \mathrm{Cu}_{3} \mathrm{O}_{10-\delta}(\mathrm{y}=0.25,0.5,0.75,1.0)$ superconductor samples [143] the ability of significant $T_{c}(0)$ enhancement by self doping [146] because it has carbon in the charge reservoir layer in contrast to $\mathrm{Cu}_{1-\mathrm{x}} \mathrm{Tl}_{\mathrm{x}}-1223$ in which change of state of thallium promotes the optimum holes doping in $\mathrm{CuO}_{2}$ planes.

\section{Conclusions}

It is concluded from the above detailed review of Tl-12(n-1) $n$ and $\mathrm{Cu}-12(n-1) n$ compounds that the superconductors of these two families have low anisotropy as compared to other cuprate families. These compounds due to their lower anisotropy have the ability to carry very high current densities of the order of 104-106 A/ $\mathrm{cm}^{2}$ in applied magnetic fields and have got potential in device fabrication. In both these families the higher critical temperature is achieved in a compound with $n=3$ member. The $\mathrm{Cu}-1223$ has lower anisotropy than that of Tl-1223 but its preparation is possible only under high pressure (4GPa). The high pressure synthesis hinders the preparation of this compound for large scale applications. But the substitution of thallium at the copper site in the charge reservoir layer of $\mathrm{Cu}-1223$ results in a new compound CuTl-1223, which has low anisotropy, higher critical temperature and critical current density. The substitution of thallium makes it possible to prepare this compound at normal pressure. We have also seen that the anisotropy of these compounds can be lowered by increasing the coupling between the $\mathrm{CuO}_{2}$ planes. The increased inter-plane coupling is achieved by substituting smaller sized elements at $\mathrm{Ca}$ site, such as $\mathrm{Mg}$ and $\mathrm{Be}$. This review article would be useful in the understanding and synthesis of new superconductors with low anisotropy and would help to enhance their superconducting properties.

\section{REFERENCES}

[1] Z. Z. Sheng and A. M. Hermann, Nature, Vol. 332, pp. 55, 1988.

[2] Z. Z. Sheng, A. M. Hermann, A. E. Ali, C. Almasan, J. Estrada, T. Datta, and R. J. Matson, Phys. Rev. Lett., Vol. 60, pp. 937, 1988.

[3] Z. Z. Sheng and A. M. Hermann, Nature, Vol. 332, pp. 138, 1988.

[4] Graziella Malandrino, Darrin S. Richeson, Tobin J. Marks, Donald C. De Groot, Jon L. Schindler, and Carl R. Kannewurf, Appl. Phys. Lett., Vol. 58, pp. 182, 1991.

[5] M. L. Chu, H. L. Chang, C. Wang, J. Y. Juang, T. M. Uen, and Y. S. Gou, Appl. Phys. Lett., Vol. 59, pp. 1123, 1991.

[6] W. L. Oslon, M. M. Eddy, T. W. James, R. B. Hammond, G. Gruner, and L. Drabeck, Appl. Phys. Lett., Vol. 55, pp. 188, 1989.

[7] M. Kikuchi, T. Kajitani, T. Suzuki, S. Nakajima, K. Hiraga, N. Kobayashi, H. Iwasaki, Y. Syono, and Y. Muto, Jpn. J. Appl. Phys., Vol. 28, pp. L382, 1989.

[8] S. S. P. Parkin, V. Y. Lee, E. M. Engler, A. I. Nazzal, T. C. Huang, G. Gormau, R. Savoy, and R. Beyer, Phys. Rev. 
Lett., Vol. 60, pp. 2539, 1988.

[9] I. K. Schuller and J. D. Jorgensen, Mater. Res. Bull. XIV, pp. 27, 1989.

[10] A. W. Sleight, M. A. Subramanian, and C. C. Torardi, Mater. Res. Bull. XIV, pp. 45, 1989.

[11] C. Martin, C. Michel, A. Maignan, M. Hervieu, and B. Raveau, C. R. Acad. Sci. Ser.2, Vol. 307, pp. 27, 1988.

[12] Chan Park and Robert L. Synder, J. Am. Ceram. Soc., Vol. 78, pp. 3171, 1995.

[13] J. B. Parise, J. Gopalkrishnan, M. A. Subramanian, and A. W. Sleight, J. Solid State Chem., Vol. 76, pp. 432, 1988.

[14] Y. Tang, B. Lin, D. Zhou, W. Zhu, F. Chen, N. Li, K. Chen, and G. Lu, Mod. Phys. Lett. B, Vol. 3, pp. 853, 1989.

[15] D. S. Ginley, J. F. Kwak, R. P. Hellmer, R. J. Baughman, E. L. Venturini, M. A. Mitchell, and B. Morosin, Physica C, Vol. 156, pp. 592, 1988.

[16] W. L. Olson, M. M. Eddy, T. W. James, R. B. Hammond, G. Gruner, and L. Drabeck, Appl. Phys. Lett., Vol. 55, pp. $188,1989$.

[17] W. Y. Lee, V. Y. Lee, J. Salem, T. C. Huang, R. Savoy, D. C. Bullock, and S. S. P. Parkin, Appl. Phys. Lett., Vol. 53, pp. 329, 1988.

[18] D. S. Ginley, J. F. Kwak, R. P. Hellmer, R. J. Baughman, E. L. Venturini, and B. Morosin, Appl. Phys. Lett., Vol. 53, pp. 406, 1988.

[19] K. K. Verma, G. D. Verma, R. S. Tiwari, and O. N. Srivastava, Jpn. J. Appl. Phys., Vol. 29, pp. L880, 1990.

[20] W. Y. Lee, J. Salem, V. Lee, D. Deline, T. C. Huang, R. Savoy, J. Duran, and R. L. Sandstrom, Physica C, Vol. 160, pp. 5117, 1989.

[21] H. L. Chang, C. Wang, M. L. Chu, T. M. Uen, and Y. S. Gou, Jpn. J. Appl. Phys., Vol. 28, pp. L631, 1989.

[22] H. S. Koo, W. M. Hurng, W. H. Lee, T. Y. Tseng, M. Chen, and J. R. Lo, Appl. Phys. Lett., Vol. 62, pp. 3354, 1993.

[23] D. Thopart, J. Hejtmanek, D. Pelloquin, C. Martin, and A. Maignan, Physica C, Vol. 336, pp. 143, 2000.

[24] Z. Zhang, C. C. Chen, C. M. Lieber, B. Morosin, D. S. Ginley, and E. L. Venturini, Phys. Rev. B, Vol. 45, pp. 987, 1992.

[25] D. T. Jover, R. J. Wijngaarden, R. Griessen, E. M. Haines, J. L. Tallon, and R. S. Liu, Phys. Rev. Lett., Vol. 54, pp. 10175, 1996.

[26] Ph. Galez, Th. Hopfinger, J. L. Soubeyroux, M. Lomello-Tafin, Ch. Opagiste, Ch. Bertrand, and J. L. Jorda, Physica C, Vol. 372, pp. 1137, 2002.

[27] S. H. Liou and C. Y. Wu, Appl. Phys. Lett., Vol. 60, pp. 2803, 1992.

[28] S. Matsuda, S. Takeuchi, A. Soeta, T. Suzuki, K. Aihara, and T. Kamo, Jpn. J. Appl. Phys., Vol. 27, pp. 2062, 1988.

[29] T. S. Kayed, Cryst. Res. Technol., Vol. 38, pp. 946, 2003.

[30] A. Soeta, T. Suzuki, S. Takeuchi, T. Kamo, K. Usami, and S. Matsuda, Jpn. J. Appl. Phys., Vol. 28, pp. L1186, 1989.

[31] S. N. Bhatia, P. Chowdhury, S. Gupta, and B. D. Padalia, Phys. Rev. B, Vol. 66, pp. 214523, 2002.
[32] Z. Z. Sheng, L. Sheng, H. M. Su, and A. M. Hermann, Appl. Phys. Lett., Vol. 53, pp. 2686, 1988.

[33] R. M. Hazen, L. W. Finger, R. J. Angel, C. T. Prewitt, N. L. Ross, C. G. Hadidiacos, P. J. Heaney, D. R. Veblen, Z. Z. Sheng, A. El Ali, and A. M. Hermann, Phys. Rev. Lett., Vol. 60, pp. 1657, 1988.

[34] F. Goutenoire, A. Maignan, G. Van Tendello, C. Martin, C. Michel, M. Hervieu, and B. Raveau, Solid State Commun., Vol. 90, pp. 47, 1994.

[35] A. Poddar, B. Bandyopadhyay, and B. Chattopadhyay, Physica C, Vol. 390, pp. 120, 2003.

[36] Y. Idemoto, M. Matsuzawa, N. Koura, K. Takeuchi, J. W. Richardson Jr., and Chun- K. Loong, Solid State Commun., Vol. 131, pp. 513, 2004.

[37] T. Tatsuki, A. Tokiwa-Yamamoto, T. Tamura, X. J. Wu, Y. Moriwaki, S. Adachi, and K. Tanabe, Physica C, Vol. 273, pp. 65, 1996.

[38] Y. X. Jia, C. S. Lee, and A. Zettl, Physica C, Vol. 234, pp. 24, 1994.

[39] C. Y. Huang, H. H. Tai, and M. K. Wu, Mod. Phys. Lett. B, Vol. 3, pp. 525, 1989.

[40] M. Yang, Y. H. Kao, Y. Kin, and K. W. Wong, Phys. Rev. B, Vol. 50, pp. 13653, 1994.

[41] A. Podder, P. Mandal, A. N. Das, and B. Ghosh, Phys. Rev. B, Vol. 44, pp. 2757, 1991.

[42] Misra, Y. Song, P. P. Crooker, J. R. Gaines, and A. H. Cardona, Appl. Phys. Lett., Vol. 59, pp. 863, 1991.

[43] P. Bramley, S. M. Morley, C. R. M. Grovenor, and B. Pecz, Appl. Phys. Lett., Vol. 66, pp. 517, 1995.

[44] D. Weaver, M. E. Reeves, G. P. Summers, and R. J. Soulen, Appl. Phys. Lett., Vol. 63, pp. 252, 1993.

[45] W. L. Holstein, L. A. Parisi, D. W. Face, X. D. Wu, S. R. Foltyn, and R. E. Muenchausen, Appl. Phys. Lett., Vol. 66 , pp. 517, 1995.

[46] A. H. Cardona, H. Suzuki, T. Yamashita, K. H. Young, and L. C. Bourne, Appl. Phys. Lett., Vol. 62, pp. 411, 1993.

[47] Sundaresan, H. Asada, A. Crisan, J. C. Nie, H. Kito, A. Iyo, Y. Tanaka, M. Kusunoki, and S. Ohshima, IEEE Trans. Appl. Supercond., Vol. 13, pp. 2913, 2003.

[48] J. Miller, J. G. Hu, J. D. Hettinger, K. E. Gray, J. E. Tkaczyk, J. Deluca, P. L. Karas, J. A. Sutliff, and M. F. Garauskas, Appl. Phys. Lett., Vol. 63, pp. 556, 1993.

[49] J. Y. Juang, J. H. Horng, S. P. Chen, C. M. Fu, K. H. Wu, T. M. Uen, and Y. S. Gou, Appl. Phys. Lett., Vol. 60, pp. 885,1995 .

[50] A. Sundaresan, H. Asada, A. Crisan, J. C. Nie, H. Kito, A. Iyo, T. Tanaka, M. Kusunoki, and S. Oshima, Physica C, Vol. 388, pp. 473, 2003.

[51] Iyo, Y. Ishiura, Y. Tanaka, P. Badica, K. Tokiwa, T. Watanabe, and H. Ihara, Physica C, Vol. 370, pp. 205, 2002.

[52] W. Mexner, J. Hoffmann, S. Heede, K. Heinemann, H. C. Freyhardt, F. Ladenberger, and E. Schwarzmann, Z. Phys. B, Vol. 101, pp. 181, 1996.

[53] N. Zheng, J. D. Johnson, A. R. Jones, A. M. Campbell, W. 
Y. Liang, T. Doi, M. Okada, and K. Higashyama, J. Appl. Phys., Vol. 77, pp. 5287, 1995.

[54] R. T. Liu, S. L. Yan, L. Fang, and M. He, Supercond. Sci. Technol., Vol. 14, pp. 948, 2001.

[55] R. S. Liu, D. N. Zheng, J. W. Loram, K. A. Mirza, A. M. Campbell, and P. P. Edwards, Appl. Phys. Lett., Vol. 60, pp. 1019, 1992.

[56] T. Jover, H. Wilhelm, R. J. Wijngarden, and R. S. Liu, Phys. Rev. B, Vol. 55, pp. 11832, 1997.

[57] R. S. Liu, P. P. Edwards, Y. T. Huang, S. F. Wu, and P. T. Wu, J. Solid State Chem., Vol. 86, pp. 334, 1990.

[58] R. S. Liu and P. P. Edwards, Physica C, Vol. 185, pp. 655, 1991.

[59] R. Abd-Shukor, B. Yatim, and R. S. L. Lau, J. Mater. Sci. Lett., Vol. 16, pp. 818, 1997.

[60] R. Abd-Shukor and K. S. Tee, J. Mater. Sci. Lett., Vol. 17, pp. 103, 1997.

[61] R. Abd-Shukor and N. A. N. Jaffar, J. Mater. Sci., Vol. 10, pp. 677, 1999.

[62] M. P. Siegal, E. L. Venturini, P. P. Newcomer, B. Morosin, D. L. Overmyer, F. Dominguez, and R. Dunn, Appl. Phys. Lett., Vol. 67, pp. 3966, 1995.

[63] H. Kotegawa, Y. Tokunga, K. Ishida, G. Q. Zheng, Y. Kitwka, A. Iyo, Y. Tanaka, and H. Ihara, Phys. Rev. B, Vol. 65, pp. 18504, 2002.

[64] H. Yamauchi and M. Karppinen, J. Supercond., Vol. 11, pp. 43, 1998.

[65] A. Iyo, Y. Aizawa, Y. Tanaka, M. Tokumoto, K. Tokiwa, T. Watanabe, and H. Ihara, Physica C, Vol. 357, pp. 324, 2001.

[66] O. Heiml, G. Gritzner, S. Tonies, H. W. Weber, J. Keckes, and B. Ortner, Supercond. Sci. Technol., Vol. 15, pp. $1592,2002$.

[67] R. E. Gladyshevskii, E. Bellingeri, F. Marti, and R. Flukiger, J. Supercond., Vol. 11, pp. 109, 1998.

[68] M. Paranthaman, J. R. Thompson, A. Goyal, A. J. Pedraza, and M.Kroeger, Appl. Phys. Lett., Vol. 67, pp. 294, 1995.

[69] A. M. Panich, S. D. Goren, L. Frenkel Ben-Yakar, M. Eder, and G. Gritzner, Physica C, Vol. 356, pp. 129, 2001.

[70] Hase, N. Hamada, A. Iyo, N. Terada, Y. Tanaka, and H. Ihara, Physica C, Vol. 357, pp. 153, 2001.

[71] L. P. Cook, W. Wong-Ng, and P. Paranthaman, J. Res. Natl. Inst. Stand. Technol., Vol. 101, pp. 675, 1996.

[72] T. Kaneko, T. Wada, H. Yamauchi, and S. Tanaka, Appl. Phys. Lett., Vol. 56, pp. 1281, 1990.

[73] A. Kikuchi, K. Inoue, and Tachikawa, Physica C, Vol. 337, pp. 180, 2000.

[74] Z. F. Rent and J. H. Wang, Appl. Phys. Lett., Vol. 61, pp. $1715,1992$.

[75] Chiang, C. Y. Shei, S. F. Wu, and Y. T. Huang, Appl. Phys. Lett., Vol. 58, pp. 2435, 1991.

[76] S. Adachi, T. Shibata, T. Tatsuki, T. Tamura, K. Tanabe, S. Fujihara, and T. Kimura, Physica C, Vol. 324, pp. 15, 1995.
[77] W. Konig, M. Mair, and G. Gritzner, J. Supercond., Vol. 11, pp. 107, 1998.

[78] Y. T. Huang, S. F. Wu, C. K. Chiang, and W. H. Lee, Appl. Phys. Lett., Vol. 57, pp. 2354, 1991.

[79] M. Enengl, E. Kuzmann, Z. Homonnay, and G. Gritzner, Physica C, Vol. 377, pp. 565, 2002.

[80] T. Kamo, T. Toi, A. Soeta, T. Yuasa, N. Inoue, K. Aihara, and S. Matsuda, Appl. Phys. Lett., Vol. 59, pp. 3186, 199.

[81] T. Doi, T. Nabatame, T. Kamo, and S. P. Matsuda, Supercond. Sci. Technol., Vol. 4, pp. 488, 1991.

[82] R. Zalecki, A. Kolodziejczyk, J. Chmist, W. Konig, and G. Gritzner, Physica C, Vol. 341, pp. 2049, 2000.

[83] S. Matsuda, S. Takeuchi, A. Soeta, T. Suzuki, K. Aihara, and T. Kamo, Jpn. J. Appl. Phys., Vol. 27, pp. 2062, 1988.

[84] R. J. McNeely, J. A. Belot, B. J. Hinds, T. J. Marks, J. L. Schindler, X. F. Zhang, and D. J. Miller, Appl. Phys. Lett., Vol. 71, pp. 1243, 1997.

[85] T. L. Aselage, E. L. Venturini, and S. B. Van Deusen, J. Appl. Phys., Vol. 75, pp. 1023, 1994.

[86] T. L. Aselage, E. L. Venturini, S. B. Van Deusen, T. J. Headley, M. O. Eatough, and J. A. Voigt, Physica C, Vol. 203, pp. 25, 1992.

[87] Oshima, T. Atou, M. Kikuchi, and Y. Syono, Physica C, Vol. 282, pp. 827, 1997.

[88] A. Iyo, Y. Tanaka, Y. Ishiura, M. Tokumoto, K. Tokiwa, T. Watanabe, and H. Ihara, Supercond. Sci. Technol., Vol. 14, pp. 504, 2001.

[89] J. L. Gonzalez, E. V. L. de Mello, E. S. Yugue, M. T. D. Orlando, and E. Baggio-Saitovitch, Physica C, Vol. 384, pp. 102, 2003.

[90] Y. S. Sung, X. F. Zhang, P. J. Kostic, and D. J. Miller, Appl. Phys. Lett., Vol. 69, pp. 3420, 1996.

[91] A. Kikuchi, T. Kinosita, N. Nishikawa, S. Komiya, and K. Tachikawa, Jpn. J. Appl. Phys., Vol. 27, pp. L167, 1995.

[92] M. Engel and G. Gritzner, Supercond. Sci. Technol., Vol. 16, pp. 956, 2003.

[93] N. M. Hamdan, Kh. A. Ziq, and A. S. Al-Harthi, Physica C, Vol. 314, pp. 125, 1999.

[94] Th. Hofinger, M. Lomello-Tafin, J. L. Jorda, Ph. Galez, M. Couach, R. E. Gladyshevskii, and J. L. Soubeyroux, Physica C, Vol. 351, pp. 53, 2001.

[95] M. H. Eder and G. Gritzner, Supercond. Sci. Technol., Vol. 18, pp. 87, 2005.

[96] A. I. Abou-Aly, I. H. Ibrahim, and R. Awad, J. Mater. Sci., Vol. 35, pp. 2893, 2000.

[97] A. I. Abou-Aly, R. Awad, and N. H. Mohammad, J. Mag. \& Magnetic Materials, Vol. 226, pp. 328, 2001.

[98] Gritzner, M. Eder, A. Cigan, J. Manka, G. Plesch, and V. Zrubec, Physica C, Vol. 366, pp. 169, 2002.

[99] E. Kuzmann, M. Mair, Z. Klencar, A. Vertes, Z. Homonnay, and G. Gritzner, Physica C, Vol. 319, pp. 12, 1999.

[100] N. M. Hamdan and J. Low Temp. Phys., Vol. 117, pp. 1187, 1999. 
[101] S. Isber, R. Awad, A. I. Abou-Aly, M. Tabbal, and J. M. Kaouar, Supercond. Sci. Technol., Vol. 18, pp. 311, 2005.

[102] M. Enengl, E. Kuzmann, Z. Homonnay, and G. Gritzner, Physica C, Vol. 377, pp. 565, 2002.

[103] Y. Li, E. Baggio-Saitovitch, Y. B. Wang, G. H. Cao, N. Chen, Z. X. Zhao, and L. Wei, Physica C, Vol. 315, pp. 129, 1999.

[104] M. Kubberger and G. Gritzner, Physica C, Vol. 390, pp. 263, 2003.

[105] R. Awad, N. S. Aly, I. H. Ibrahim, A. I. Abou-Aly, and A. I. Saad, Physica C, Vol. 341, pp. 685, 2000.

[106] W. L. Holstein, L. A. Parisi, C. Wilker, and R. B. Flippen, Appl. Phys. Lett., Vol. 60, pp. 2014, 1992.

[107] K. F. Renk and G. Saemann-Ischenko, Appl. Phys. Lett., Vol. 65, pp. 1451, 1994.

[108] Chou, H. S. Chen, A. R. Kortan, L. C. Kimerling, F. Thiel, and M. K. Wu, Appl. Phys. Lett., Vol. 58, pp. 2836, 1991.

[109] A. Piehler, R. Low, J. Betz, R. Schonberger, and K. F. Renk, J. Appl. Phys., Vol. 74, pp. 6437, 1993.

[110] V. handy, A. Maignan, C. Martin, F. Warmont, and J. Provost, Phys. Rev. B, Vol. 56, pp. 130, 1997.

[111] P. Marsh, R. M. Fleming, M. L. Mandich, A. M. Desantolo, J. Kwo, M. Hong, and L. J. Martines-Miranda, Nature, Vol. 334, pp. 141, 1988.

[112] Mihailovic, T. Mertelj, K. F. Voss, A. J. Heeger, and N. Herron, Phys. Rev. B, Vol. 45, pp. 8016, 1992.

[113] Scherbel, M. Mans, H. Schneidenind, U. Kaiser, J. Biskupek, F. Schmidl, and P. Seidel, Phys. Rev. B, Vol. 70, pp. 104507, 2004.

[114] T. Nabatame, S. Koike, O. B. Hyun, I. Hirabayashi, H. Suhara, and K. Nakamura, Appl. Phys. Lett., Vol. 65, pp. 776, 1994.

[115] H. Takei, H. Kugai, Y. Torii, and K. Tada, Physica C, Vol. 210, pp. 109, 1993.

[116] T. Nabatame, J. Sato, Y. Saito, K. Aihara, T. Kamo, and S. Matsuda, Physica C, Vol. 193, pp. 39, 1992.

[117] M. Paranthaman, M. Foldeaki, R. Tello, and A. M. Hermann, Physica C, Vol. 219, pp. 413, 1994.

[118] Q. Jin, S. Adachi, X. J. Wu, H. Yamauchi, and S. Tanaka, Physica C, Vol. 223, pp. 238, 1994.

[119] X. J. Wu, S. Adachi, C. Q. Jin, H. Yamauchi, and S. Tanaka, Physica C, Vol. 223, pp. 243, 1994.

[120] X. J. Wu, C. Q. Jin, S. Adachi, and H. Yamauchi, Physica C, Vol. 224, pp. 175, 1994.

[121] H. Ihara, Adv. Supercond., Vol. 7, pp. 255, 1995.

[122] H. Ihara, Solid State Phys., Vol. 35, pp. 301, 2001.

[123] M. Karppinen, H. Yamauchi, Y. Morita, M. Kitabatake, T. Motohashi, R. S. Liu, J. M. Lee, and J. M. Chen, Journal of Solid State Chemistry, Vol. 177, pp. 1037, 2004.

[124] H. Ihara, K. Tokiwa, H. Ozawa, M. Hirabayashi, A. Negishi, H. Matuhata, and Y. S. Song, Jpn. J. Appl. Phys., Vol. 33, pp. L503, 1994.

[125] H. Ihara, K. Tanaka, Y. Tanaka, A. Iyo, N. Terada, M.
Tokumoto, M. Ariyama, I. Hase, A. Sundaresan, N. Hamada, S. Miyashita, K. Tokiwa, and T. Watanabe, Physica C, Vol. 341, pp. 487, 2000.

[126] H. Ihara, Physica C, Vol. 364, pp. 289, 2001.

[127] Tokiwa, H. Aota, C. Kunugi, K. Tanaka, Y. Tanaka, A. Iyo, H. Ihara, and T. Watanabe, Physica B, Vol. 284, pp. 1077, 2000.

[128] Tanaka, A. Iyo, N. Terada, K. Tokiwa, S. Miyashita, Y. Tanaka, T. Tsukamoto, S. K. Agarwal, T. Watanabe, and H. Ihara, Phys. Rev. B, Vol. 63, pp. 064508, 2001.

[129] T. Shibata, T. Tatsucki, S. Adachi, K. Tanabe, S. Fujihara, and T. Kimura, Physica C, Vol. 353, pp. 200, 2001.

[130] Nawazish A. Khan, Y. Sekita, H. Ihara, and A. Maqsood, Physica C, Vol. 377, pp. 43, 2002.

[131] Tanaka, A. Iyo, Y. Tanaka, K. Tokiwa, M. Tokumoto, M. Ariyama, T. Tsukamoto, T. Watanabe, and H. Ihara, Physica B, Vol. 284, pp. 1081, 2001.

[132] H. Ihara, Y. Sekita, F. Tateai, N. A. Khan, K. Ishida, E. Harashima, T. Kojima, H. Yamamoto, K. Tanaka, Y. Tanaka, N. Terada, and H. Obara, IEEE Trans. Appl. Supercond., Vol. 9, pp. 1551, 1999.

[133] A. Khan, Y. Sekita, F. Tateai, T. Kojima, K. Ishida, N. Terada, and H. Ihara, Physica C, Vol. 320, pp. 39, 1999.

[134] Nawazish A. Khan and A. A. Khurram, Appl. Phys. Lett., Vol. 86, pp. 152502, 2005.

[135] Nawazish A. Khan and Shahid Nawaz, IEEE Trans. Appl. Supercond., Vol. 16, pp. 1, 2006.

[136] S. K. Agarwal, A. Iyo, K. Tokiwa, Y. Tanaka, K. Tanaka, M. Tokumoto, N. Terada, T. Saya, M. Umeda and H. Ihara, Phys. Rev. B, Vol. 58, pp. 9504, 1998.

[137] Nawazish A. Khan and G. Husnain, Physica C, Vol. 436, pp. 51, 2006.

[138] Nawazish A. Khan, Asim Javaid, A. A. Khurram, and Naghma Haider, Physica C, Vol. 425, pp. 90, 2005.

[139] T. Watanabe, S. Miyashita, N. Ichioka, K. Tokiwa, K. Tanaka, A. Iyo, Y. Tanaka, and H. Ihara, Physica B, Vol. 284, pp. 1075, 2000.

[140] Terada, K. Tanaka, Y. Tanaka, A. Iyo, K. Tokiwa, T. Watanabe, and H. Ihara, Physica B, Vol. 284, pp. 1083, 2000.

[141] H. Ihara, K. Tanaka, Y. Tanaka, A. Iyo, N. Terada, M. Tokumoto, F. Tateai, M. Kawamura, K. Ishida, S. Miyashita, and T. Watanabe, Physica B, Vol. 284, pp. 1085, 2000.

[142] A. A. Khurram and Nawazish A. Khan, Supercond. Sci. Technol., Vol. 19, pp. 679, 2006.

[143] A. Khan and A. Hussain, Physica C, Vol. 449, pp. 21, 2006.

[144] T. Kawashima, Y. Matsui, and E. Takayama-Muromachi, Physica C, Vol. 224, pp. 69, 1994.

[145] H. Kito, A. Iyo, M. Hirai, A. Crisan, A. Tokumoto, S. Okayasu, M. Sasase, and H. Ihara, Physica C, Vol. 378, pp. 329, 2002.

[146] M. Hirai, A. Iyo, H. Kito, A. Crisan, K. Tokiwa, T. Watanabe, J. Arai, and Y. Tanaka, Physica C, Vol. 388, pp. 427,2003 